\title{
Soroepidemiologia da toxoplasmose e avaliação ocular pela Tela de Amsler, em pacientes da zona rural, atendidos na unidade de saúde do município de Jaguapitã, PR, Brasil
}

\author{
Seroepidemiology of toxoplasmosis and ocular evaluation by Amsler Grid in \\ patients from the rural area treated at the Jaguapitã county \\ health center, Paraná State, Brazil
}

\author{
João Luis Garcia, Italmar Teodorico Navarro, Liza Ogawa, \\ Rosangela C. de Oliveira, Simone Menezes de Faria Garcia e José Leite
}

\begin{abstract}
Resumo O objetivo do trabalho foi avaliar a soroepidemiologia do T. gondii e relato de problemas oculares em pacientes da zona rural que procuraram a unidade de saúde de Jaguapitã, Paraná. Soros de 82 pacientes foram submetidos a reação de Imunofluorescência Indireta, para detectar a presença de anticorpos anti-T. gondii da classe IgG, sendo a soropositividade considerada para diluições $\geq 1: 16$. Problemas oculares foram avaliados através da Tela de Amsler. Dos 82 soros avaliados 68 (82,9\%) foram sororeagentes a toxoplasmose e $14(17,1 \%)$ não reagentes. Os títulos mais frequentes foram de 64 (23/33,8\%) e 256 (16/23,5\%), e os maiores títulos foram de 4096 (8/11,8\%). O teste da Tela de Amsler revelou $22(26,8 \%)$ pacientes que relataram algum tipo de alteração, sendo que o sexo masculino foi um fator de proteção em relação ao sexo feminino $\left(O R=0,210,04<O R<0,86 \chi^{2}=4,98 \mathrm{p}=0,02\right)$. No presente estudo os fatores de risco avaliados pelo inquérito sócio cultural e epidemiológico não revelaram diferenças estatísticas significativas. Através do presente trabalho observou-se que o T. gondii encontra-se amplamente distribuído na população estudada.
\end{abstract}

Palavras-chaves: Toxoplasma gondii. Toxoplasmose humana. Prevalência. Soroepidemiologia.

Abstract In this study, we collected serum from 82 randomly selected patients from a rural area in Jaguapitã county, Paraná State. All sera were subjected to indirect immunofluorescence assay (IFA) to detect IgG antibodies against T. gondii. Serum titers $\geq+16$ were considered positive. Of the 82 evaluated sera, 68 (82.9\%) were positive to toxoplasmosis and $14(17.1 \%)$ were nonreactive. The most common titers found were 64 (23/33.8\%) and 256 (16/23.5\%), the highest titer being 4096 (8/11.8\%). The 82 patients were also evaluated by the Amsler Grid test, with 22 (26.8\%) patients presenting at least one alteration in this test. Masculinity was found to be a protection factor in the Amsler grid test $\left(O R=0.210 .04<O R<0.86 \chi^{2}=4,98 \mathrm{p}=0,02\right)$. There were no significant statistical differences related to the epidemiological investigation. We concluded that T. gondii has a wide distribution in the population studied.

Key-words: Toxoplasma gondii. Human toxoplasmosis. Prevalence. Seroepidemiology.

Secretaria Municipal de Saúde, Jaguapitã, Departamento de Medicina Veterinária Preventiva e de Serviço Social da Universidade Estadual de Londrina, PR.

Suporte Financeiro: CPG-UEL/CAPES/CNPq.

Endereço para correspondência: Prof. Italmar Teodorico Navarro. Depto de Medicina Veterinária Preventiva/CCA/UEL. Caixa Postal 6001, 86051-970 Londrina, PR.

Tel: 5543 371-4485; Fax: 5543 371-4714.

Recebido para publicação em 20/8/98. 
A toxoplasmose é causada pelo Toxoplasma gondii ${ }^{20}$ doença que acomete uma infinidade de espécies, incluindo os mamíferos, répteis, anfíbios e aves ${ }^{22}$, sendo considerada uma das parasitoses mais freqüentes no homem e talvez nos animais homeotérmicos ${ }^{3}$. Os gatos e outros felídeos são os únicos hospedeiros definitivos da doença ${ }^{1017}$, nestes ocorre um ciclo de vida, no intestino delgado, distinto dos outros hospedeiros, chamado enteroepitelial ${ }^{15}$.

O homem, pode adquirir a doença após o nascimento, principalmente pelo consumo de carnes cruas ou mal cozidas contaminadas com cistos teciduais, bem como alimentos e águas contaminadas pelos oocistos ${ }^{1924}$. Leite não pasteurizado, ovos, transfusões sanguíneas e transplante de órgãos, são outras vias de transmissão citadas ${ }^{8}$.

A infecção toxoplásmica nos seres humanos, é muito comum, porém os sinais clínicos não o são, salvo em duas categorias, àqueles indivíduos com o sistema imune deprimido (quimioterapia para o câncer, tratamento para transplantados e indivíduos HIV positivos) e para mulheres que contraem primariamente a infecção durante a gestação ${ }^{6}$. Roberts e cols ${ }^{21}$ estimaram em 5,3 bilhões de dólares o custo anual das perdas com cuidados médicos, perda em produtividade e custos com educação especial para a toxoplasmose congênita nos Estados Unidos no ano de 1993.

A forma congênita ocorre, quando a mãe sofre prima infecção na época da gestação e o parasita atravessa a barreira placentária, posteriormente infectando o feto, que pode apresentar lesões severas, ou nascimento de crianças aparentemente saudáveis que posteriormente apresentam alterações ${ }^{5}$.

O T. gondii é o agente etiológico mais freqüente nas uveítes de localização posterior na população humana no Brasil ${ }^{16}$. A toxoplasmose ocular pode ter origem congenita ou adquirida ${ }^{18}$. Alguns autores relataram ser a toxoplasmose ocular adquirida, bastante comum no Sul do Brasil ${ }^{1423}$.

O objetivo do presente trabalho foi estudar a soroepidemiologia da toxoplasmose e avaliar problemas oculares através da utilização da tela de Amsler ${ }^{2}$, como triagem, em pacientes da zona rural, atendidos na unidade de saúde do município de Jaguapitã, Paraná, Brasil.

\section{MATERIAL E MÉTODOS}

As 82 amostras de soro, de indivíduos de ambos os sexos, com idades que variaram de 7 a 82 anos, foram colhidas no período de março à maio de 1996, de pacientes atendidos na unidade de saúde do município de Jaguapitã, que encontra-se localizado ao norte do Estado do Paraná, sendo formado por 10612 habitantes, com 3142 na zona rural ${ }^{11}$. A amostragem fol coletada aleatoriamente e representou 10,06\% dos pacientes da zona rural que procuraram a unidade de saúde no período estudado.

Amostras de 2 a $10 \mathrm{ml}$ de sangue foram colhidas por punção venosa, em tubos de ensaio estéreis. No laboratório estas amostras eram incubadas em Banho Maria a $37^{\circ} \mathrm{C}$ por duas horas até retração do coágulo, em seguida centrifugados a 3000 rpm durante 15 minutos. Posteriormente, os soros eram retirados e transferidos para frascos estéreis, identificados e armazenados a $-20^{\circ} \mathrm{C}$, até a realização dos exames. Todas as amostras colhidas eram acompanhadas de uma ficha sóciocultural e epidemiológica, que contemplava os aspectos relativos aos dados de identificação e os fatores epidemiológicos do agente versus paciente.
Com o propósito de avaliar possíveis alterações oculares, utilizou-se a Tela de Amsler ${ }^{2}$, como exame de triagem nas 82 pessoas submetidas a sorologia. O teste consistia em cobrir-se um dos olhos, solicitava-se que olhassem para o ponto central e mantendo essa posição descrevessem, se os quadrados e as linhas permaneciam inalterados e retas. O teste foi realizado para ambos os olhos, os que relatassem qualquer alteração eram identificados assim como o olho afetado.

Os soros foram submetidos a reação de imunofluorescência indireta (RIFI) para detecção de anticorpos anti-Toxoplasma gondii da classe $\operatorname{lgG}$, conforme técnica descrita por Camargo ${ }^{7}$, utilizando-se soro anti-IgG humano, produzido a partir de inoculações em coelhos, conjugado ao isotiocianato de fluresceína da marca SigmaChemical. Em todas as reações foram incluídos soros padrões positivo e negativo previamente conhecidos. A leitura foi realizada em microscópio de imunofluorescência da marca NIKON. A positividade foi considerada para diluições $\geq 1: 16$.

A magnitude da associação dos fatores de risco foi determinada pela razão de chances $(\mathrm{OR})$, e a significância foi determinada quando 
$95 \%$ do intervalo de confiança não incluiu o 1. A análise de associação entre os grupos foi testada pelo teste de qui-quadrado $\left(\chi^{2}\right)$ com significância estatística determinada se $p \leq 0,05$.

\section{RESULTADOS}

Dos 82 pacientes estudados, 68 (82,9\%) e $14(17,1 \%)$ não reagentes, conforme apresentaram-se sororeagentes a toxoplasmose, demostrado pela Tabela 1. Os títulos mais

Tabela 1 - Detecção de anticorpos anti-Toxoplasma gondii através da reação de imunofluorescência indireta - lgG (RIFl-lgG), em soros de pacientes oriundos da zona rural, atendidos na unidade de saúde, correlacionadas ao sexo, no município de Jaguapitã, Estado do Paraná, Brasil, 1996.

\begin{tabular}{|c|c|c|c|}
\hline \multirow[b]{2}{*}{ Sexo } & \multicolumn{2}{|c|}{ RIFI-IgG } & \multirow[b]{2}{*}{$\begin{array}{l}\text { Total } \\
\mathrm{n} \% \% \\
\end{array}$} \\
\hline & $\begin{array}{c}\text { reagentes } \\
n^{\circ} / \% \\
\end{array}$ & $\begin{array}{c}\text { não reagentes } \\
n^{\circ} / \%\end{array}$ & \\
\hline Masculino & $24 / 82,8$ & $5 / 17,2$ & $29 / 35,3$ \\
\hline Feminino & $44 / 83,0$ & $9 / 17,0$ & $53 / 64,7$ \\
\hline Total & $68 / 82,9$ & $14 / 17,1$ & $82 / 100,0$ \\
\hline
\end{tabular}

frequentes foram de $64(33,8 \%)$ e $256(23,5 \%)$ e o maior título encontrado foi de $4096(11,8 \%)$, que pode ser observado na Tabela 2.

Através do inquérito epidemiológico não se verificou diferenças estatísticas significativas em relação aos fatores sexo e faixas etárias (Tabelas 1 e 3). Da mesma forma o hábito de consumir leite cru, hábito de consumir carne crua, hábito de consumir hortaliças cruas, contato com animais, contato com felinos, produção de subprodutos

Tabela 2 - Recíproca dos títulos de anticorpos anti-Toxoplasma gondii, através da reação de imunofluorescência indiretaIgG (RIFl-lgG), em soros de pacientes da zona rural atendidos na unidade de saúde do município de Jaguapitã, Estado do Paraná, Brasil, 1996.

\begin{tabular}{lrc}
\hline Título de Anticorpo & \multicolumn{2}{c}{ Reagentes } \\
\cline { 2 - 4 } & $\mathrm{n}^{\circ}$ & 19,1 \\
\hline 16 & 13 & 33,8 \\
64 & 23 & 23,5 \\
256 & 16 & 11,8 \\
1024 & 8 & 11,8 \\
4096 & 8 & 100,0 \\
\hline Total & 68 & 100 \\
\hline
\end{tabular}

Tabela 3 - Detecção de anticorpos anti-Toxoplasma gondii através da reação de imunofluorescência indireta - lgG (RIFI-lgG), em soros de pacientes oriundo da zona rural atendidos na unidade de saúde, segundo as faixas etárias (anos), no município de Jaguapitã, Estado do Paraná, Brasil, 1996.

\begin{tabular}{|c|c|c|c|}
\hline \multirow[b]{2}{*}{$\begin{array}{l}\text { Faixas etárias } \\
\text { (anos) }\end{array}$} & \multicolumn{2}{|c|}{ RIFI-IgG } & \multirow[b]{2}{*}{$\begin{array}{l}\text { Total } \\
\mathrm{n}^{\circ} / \%\end{array}$} \\
\hline & $\begin{array}{c}\text { reagentes } \\
n^{\circ} / \%\end{array}$ & $\begin{array}{c}\text { não reagentes } \\
n^{\circ} / \%\end{array}$ & \\
\hline$\leq 14$ & $5 / 62,5$ & $3 / 37,5$ & $8 / 9,7$ \\
\hline$\geq 15 a \leq 40$ & $34 / 82,9$ & $7 / 17,1$ & $41 / 50,0$ \\
\hline$\geq 41$ & $29 / 87,8$ & $4 / 12,2$ & $33 / 40,3$ \\
\hline Total & $68 / 82,9$ & $14 / 17,1$ & $82 / 100,0$ \\
\hline
\end{tabular}


de origem animal e atividade desenvolvida não influenciaram na distribuição dos sororreagentes.

Aavaliação da tela de Amsler revelou que dos 82 paciente que participaram do teste, $22(26,8 \%)$ relataram algum tipo de alteração ocular, sendo que destes 17 (77,3\%) foram sororreagentes a toxoplasmose, conforme demostrado pela Tabela 4. Verificou-se também um fator de proteção do sexo masculino em relação ao sexo feminino para alterações na tela de Amsler (OR =0,21 / 0,04 < $\mathrm{OR}<0,86 \chi^{2}=4,98 p=0,02$ ), conforme demostra a Tabela 5 .

Tabela 4 - Detecção de anticorpos anti-Toxoplasma gondii através da reação de imunofluorescência indireta - IgG (RIFl-lgG), em soros de pacientes oriundo da zona rural atendidos na unidade de saúde, relacionados as alterações relatadas no teste da tela de Amsler, no município de Jaguapitã, Estado do Paraná, Brasil, 1996.

\begin{tabular}{lccc}
\hline \multirow{2}{*}{ Tela de Amsler } & \multicolumn{2}{c}{ RIFI-IgG } & Total \\
\cline { 2 - 4 } & reagentes & não reagentes & $\mathrm{n}^{\circ} / \%$ \\
\hline Com alteração & $\mathrm{n}^{\circ} / \%$ & $5 / 22,7$ & $22 / 26,8$ \\
Sem alteração & $17 / 77,3$ & $9 / 15,0$ & $60 / 73,2$ \\
\hline Total & $51 / 85,0$ & $14 / 17,1$ & $82 / 100,0$ \\
\hline
\end{tabular}

$\left(\chi^{2}=0,24 p=0,62\right)$

Tabela 5 - Resultados das alterações relatadas no teste da tela de Amsler, nos pacientes da zona rural atendidos na unidade de saúde, correlacionadas ao fator sexo, no município de Jaguapitã, Estado do Paraná, Brasil, 1996.

\begin{tabular}{lccc} 
& & & Sexo \\
\cline { 2 - 3 } Tela de Amsler & masculino & feminino & Total \\
& $\mathrm{n}^{\circ} / \%$ & $\mathrm{n}^{\circ} / \%$ & $\mathrm{n}^{\circ} / \%$ \\
\hline Com alteração & $3 / 13,6$ & $19 / 86,4$ & $22 / 26,8$ \\
Sem alteração & $26 / 43,3$ & $34 / 56,7$ & $60 / 73,2$ \\
\hline Total & $29 / 35,4$ & $53 / 64,6$ & $82 / 100,0$ \\
\hline
\end{tabular}

$\left(\mathrm{OR}=0,210,04<\mathrm{OR}<0,86 \chi^{2}=4,98 p=0,02\right)$.

\section{DISCUSSÃO}

A soropositividade de $82,9 \%$ para a toxoplasmose nos pacientes estudados, é bastante significativo quando comparado aos estudos anteriores, onde moradores de propriedades rurais, também do município de Jaguapitã, apresentaram uma soroprevalência de $65,8 \%$ para a toxoplasmose ${ }^{12}$, bem como aos estudos com pacientes da zona rural que procuraram a unidade de saúde do município de Guaraci ${ }^{13}$ e no município de Londrina ${ }^{4}$ ambos na região norte do Estado do Paraná, que verificaram uma soropositividade para a toxoplasmose, de $71 \%$ e $75 \%$, respectivamente.

Os títulos de anticorpos mais freqüentes observados no estudo atual refletem semelhanças com investigações anteriores ${ }^{41213}$. O maior título encontrado no levantamento sorológico (4.096), equipara-se ao de Barros e cols ${ }^{4}$ onde verificaram títulos de 8.192, diferenciando-se porém dos títulos de até 65.536 observados por Garcia $^{12} \mathrm{e}$ Garcia e Navarro ${ }^{13}$.

Não foram verificadas diferenças estatísticas significativas, no trabalho atual, quanto ao fator sexo, resultados estes que já foram descritos anteriormente ${ }^{4121324}$ assim como, a análise das faixas etárias, não revelaram diferenças significativas ${ }^{4}{ }^{13}$. Da mesma forma os fatores de risco avaliados através do inquérito epidemiológico, não revelaram diferenças estatísticas significativas, na distribuição dos sororreagentes ${ }^{12}$. Esses achados demonstram, que os pacientes estiveram expostos a fontes comuns de infecção, independente do sexo, faixas etárias, atividades desenvolvidas ou hábitos alimentares.

O estudo da tela de Amsler demonstrou que $22(26,8 \%)$ pacientes relataram algum tipo de alteração ocular, sendo que $17(77,3 \%)$ foram sororeagentes a toxoplasmose, e não houve associação entre relato de alteração na tela e sororeagente a toxoplasmose .

Estes resultados assemelham-se aos encontrados por Garcia $^{12}$ onde estudando 345 pacientes oriundos de propriedades rurais no município de Jaguapitã, verificou que 75 (21,8\%) apresentaram algum tipo de alteração na tela de 
Amsler, e destes, 58 (77,3\%) foram sororreagentes ao $T$. gondii, diferem porém quando verificou um risco maior de soropositividade ao Toxoplasma nos indivíduos que relataram alteração na Tela de Amsler.

O estudo revelou um fator de proteção do sexo masculino $(\mathrm{OR}=0,210,04<\mathrm{OR}<0,86) \mathrm{em}$ relação ao sexo feminino, quando comparado ao risco de apresentar alteração na tela de Amsler, dados estes que também foram observados em moradores da zona rural do município de Jaguapitã ${ }^{12}$.

ATela de Amsler foi descrita como um método simples e rápido para avaliar o campo visual macular ${ }^{2}$, contudo estudos recentes tem demonstrado uma baixa sensibilidade e especificidade do teste ${ }^{1}$.

O presente estudo demostrou uma elevada soropositividade ao $T$. gondiinaqueles pacientes que procuraram a unidade de saúde do município de Jaguapitã, Paraná, Brasil. O teste da Tela de Amsler, bem como os pacientes do sexo feminino apresentaram maiores alterações na tela que os do sexo masculino. Maiores estudos mostrando a correlação entre os resultados da Tela de Amsler e possíveis lesões oculares da toxoplasmose devem ser realizados.

\section{REFERÊNCIAS BIBLIOGRÁFICAS}

1. Achard OA, Safran AB, Duret FC, Ragama E. Role of the completion phenomenon in the evaluation of Amsler grid results. American Journal of Ophthalmology 120:322-329, 1995.

2. Amsler M. Earliest symptoms of diseases of the macula. British Journal Ophthalmology 37:521-537, 1953.

3. Aptl W, Thermann E, Niedman G, Pasmanir S. Toxoplasmosis. Santiago, Arancibia Horns, 1973.

4. Barros MAI, Navarro IT, Marana ERM, Shida PN. Toxoplasmose humana: inquérito sorológico em habitantes da região rural de Londrina - Paraná - Brasil. In: Resumos do VIII Seminário Brasileiro de Parasitologia Veterinária, Londrina, p. P16, 1993.

5. Brooks KD. Feline toxoplasmosis and human health. Veterinary Technician 13:568-563, 1992.

6. Buxton D. Toxoplasmosis: the first commercial vaccine. Parasitology Today 9:335-337, 1993.

7. Camargo ME. Improved tchnique of indirect imunofluorescence for serological diagnosis of toxoplasmosis. Revista do Instituto de Medicina Tropical de São Paulo 6:117-118, 1964.

8. Dressen DW. Toxoplasma gondii. Journal American Veterinary Medical Association 196:274-276, 1990.

9. Dubey JP. Toxoplasma, Neospora, Sarcocystis and other tissue cyst- forming of human and aniamls. In: Krier JP (ed) Parasitic protozoa. $2^{\text {nd }}$ edition, Academic Press, San Diego, p. 1-157, 1993.

10. Frenkel JK, Dubey JP, Miller NL. Toxoplasma gondii in cats fecal stages identified as coccidian oocysts. Science 167:893-896, 1970.

11. Fundação Instituto Brasileiro de Geografia e Estatística (IBGE). Censo demográfico: resultados do universo relativos às caracteristicas da população e dos domicílios, Paraná. Fundação Instituto Brasileiro de Geografia e Estatística; Rio de janeiro, n. 22,1991.

12. Garcia JL. Epidemiologia do Toxoplasma gondii na população animal e humana dentro do ecossistema da doença. Dissertação de Mestrado, Universidade Estadual de Londrina, Londrina, PR, 1998.

13. Garcia JL, Navarro IT. Levantamento soroepidemiológico da toxoplasmose em moradores da zona rural do município de Guaraci - Paraná - Brasil. Semina16:6367, 1995.

14. Glasner PD, Silveira C, Kruszon-Moran D, Martins MC, Burnier Junior M, Silveira S, Camargo ME, Nussenblatt RB, Kaslow RA, Belfort Junior R. An unusually high prevalence of ocular toxoplasmosis in southern Brazil. American Journal Ophthalmology 114:136-144, 1992.

15. Jackson MH, Hutchison WM. The prevalence and source of toxoplasma infection in the enviroment. In: Baker JR, Muller R (eds) Advances in parasitology 28, Academic Press, San Diego, p. 55-105, 1989.

16. Melamed J, Alves LS. Toxoplasmose e Deficiência Visual. In: Resumos do Congresso Brasileiro de Prevenção da Cegueira. Campinas, 1984.

17. Miller NL, Frenkel JK, Dubey JP. Oral infections with Toxoplasma cysts and oocysts in felines, other mammals and birds. Journal of Parasitology 58:928-937, 1972.

18. Montoya JG, Remington JS. Toxoplasmic chorioretinitis in the setting of acute acquired toxoplasmosis. Clinical Infectious Diseases 23: 277-282, 1996.

19. Navarro IT, Vidotto O, Giraldi N, Freire R. Estudo da resistência do Toxoplasma gondiiao efeito do cloreto de sódio e condimentos em linguiça frescal de suínos. Boletin Sanitario Panamericano 112:138-143, 1992.

20. Nicolle C, Manceaux L. Sur un protozoaire nouveau du gondii. Compte Rendu Academic Science Paris 148:369372, 1909

21. Roberts T, Murrell KD, Marks S. Economic losses caused by foodborne Parasitic deseases. Parasitology Today 10:419-423, 1994.

22. Sanchis FS. Estudo da reinfecção experimental do gato pelo Toxoplasma gondii. Tese de Livre Docente, Universidade Estadual de São Paulo, São Paulo, 1978. 
23. Silveira C, Belfort Junior M, Burnier Junior M, Nussenblatt R. Acquired toxoplasmic infection as the cause of toxoplasmic retinochoroiditis in families. American Journal of Ophtalmology 106:362-364, 1988.

24. Souza WJS, Coutinho SG, Lopes CWG, Santos CS, Neves NM, Cruz AM. Epidemiological aspects of toxoplasmosis in schoolchildren residing in localities with urban or rural caracteristics within the city of Rio de Janeiro, Brazil. Memorando do Instituto Oswaldo Cruz 82: 475-482, 1987. 